\title{
O discurso de crise da educação: crítica ao modelo de competências desde a epistemologia da educação
}

\author{
Leandro de Proença-Lopes ${ }^{1}$ \\ Faculdades Metropolitanas Unidas - FMU (Brasil) \\ Grupo de pesquisa HISULA \\ leandro_proenca@hotmail.com \\ Fellipe de Assis Zaremba ${ }^{2}$ \\ Faculdades Metropolitanas Unidas - FMU (Brasil) \\ fellipeazaremba@yahoo.com.br
}

Recepción: 22/01/2013

Evaluación: 9/05/2013

Aceptación: 28/06/2013

Artículo de Reflexión

DOI: http:/ / dx.doi.org/ 10.9757/ Rhela. 21.09

\section{RESUMO}

O presente artigo tem como objetivo analisar o discurso de crise da educação que permeia a nossa sociedade na contemporaneidade, partindo do fato de que a educação não realizou sua imediata adesão aos fundamentos propostos pela reforma da educação que procurava promover a apropriação do chamado modelo de competências. Procuramos verificar de que forma o modelo de competências tem impactado na formulação de um discurso de crise que não configura propriamente uma tarefa educacional. Para isso, desenvolvemos uma análise das reformas educacionais ocorridas nos anos
90 a partir de uma perspectiva sociológica, buscando compreender o contexto em que se produziu intensa pressão para que as escolas preparassem o trabalhador adequado às novas demandas do capital. Para a realização da tarefa proposta, consideramos ainda que o conceito de desencantamento do mundo é bastante útil para compreendermos o fascínio do fetiche do consumismo em proporção ao desencantamento da educação. Pudemos concluir que predomina a lógica de uma educação instrumental e adaptativa, e que esta se realizou na medida em que as intenções de reforma se materializavam

1 Doutor em Educação pela Universidade Nove de Julho - UNINOVE - São Paulo - Brasil. Professor de Filosofia e História da Educação nas Faculdades Metropolitanas Unidas - FMU, pesquisador grupo HISULA Universidad Pedagógica y Tecnológica de Colombia, artigo e articula o projecto de políticas públicas, reformas e movimentos estudiantiles na Colombia desenvolvido pela SGI 1295 HISULA grupo e financiado pela Direcção de Investigação da UPTC.

2 Mestre em Educação pela Universidade Nove de Julho - UNINOVE - São Paulo - Brasil. Graduado em História e Pedagogia com habilitações em Administração e Supervisão Escolar. Assessor Pedagógico da Editora Formando Cidadãos. Professor de Sociologia nas Faculdades Metropolitanas Unidas - FMU. 
em políticas públicas com o modelo de competências. Há um intenso processo de mediação entre a crise da educação e a não apropriação no espaço escolar da pedagogia das competências, pois esta conduz à impossibilidade de compreender as tarefas epistemológicas de educação, colocando sobre esta expectativas que não lhe competem, causando assim um discurso de crise que revela uma postura

The discourse of the crisis of the education: review to the model of competencies from the epistemology of education

\section{ABSTRACT}

This article aims to analyze the discourse of crisis in education that permeates our contemporary society. It is observed from the fact that education did not carry out immediately its proposed principles for the education reform, this reform looked for promoting the admission called competences model. We are trying to check how the competences model has had an impact on the manner of a discourse of the crisis which is not given an educational task. To do this, we have developed an analysis of the educational reforms that were developed in the 1990s, we attempt to understand the context from a sociological perspective, and the schools were under pressure in order to prepare adequately the new capital requirements. To carry out the proposal, we believe that the concept of world's disenchantment is useful to understand the attraction of the consumption fetishism, in relation with the disenchantment of the education. We concluded that it is predominant a logical set of instruments for education and adaptation, and that this was done to the extent that the intentions of the reform have been translated into public policies with the competences model. There is an intense process of mediation between the crisis of the education and not appropriation in the school space of the pedagogies of the competences, since this drives to the incapability to understand the epistemological tasks of the education, putting expectations in this one that are not of its competences, causing this way a speech of de alienação diante dos problemas mais amplos da sociedade.

Palavras-chave: Revista História da Educação Latino-americana, políticas educacionais, cultura escolar, modelo de competências, crise da educação, desencantamento da educação, epistemologia da educação.

El discurso de crisis de la educación: crítica al modelo de competencias desde la epistemología de la educación

\section{RESUMEN}

Este artículo tiene como objetivo analizar el discurso de crisis de la educación que impregna nuestra sociedad en la contemporaneidad, desde el hecho de que la educación no llevó a cabo su admisión inmediata a los principios propuestos por la reforma educativa que buscaba promover la apropiación del denominado modelo de competencias. Intentamos verificar cómo el modelo de competencias ha tenido un impacto en la formulación de un discurso de la crisis que no se pone propiamente como una tarea educativa. Para ello, hemos desarrollado un análisis de las reformas educativas que se produjeron en los años noventa, desde una perspectiva sociológica, buscando entender el contexto en el que se produjo una intensa presión para que las escuelas preparen adecuadamente a las nuevas exigencias del capital. Para llevar a cabo la tarea propuesta, consideramos que el concepto de desencantamiento del mundo es muy útil para entender el atractivo del fetiche del consumo en proporción con el desencantamiento de la educación. Llegamos a la conclusión de que es predominante una lógica de educación instrumental y de adaptación, y que esto se llevó a cabo en la medida en que las intenciones de la reforma se han materializado en las políticas públicas con el modelo de competencias. Hay un intenso proceso de mediación entre la crisis de la educación y la no apropiación en el espacio escolar de la pedagogía de las competencias, ya que esto conduce a la incapacidad para entender las tareas epistemológicas de la educación, 
the crisis that reveals an attitude of alienation opposite to the widest problems of the society.

Key words: Journal of the History of American Education, political educational, school culture, model of competences, crisis of the education, disenchantment of the education, epistemology of education. poniendo expectativas en esta que no son de sus competencias, causando así un discurso de la crisis que revela una actitud de alienación frente a los problemas más amplios de la sociedad.

Palabras clave: Revista Historia de la Educación Latinoamericana, politicas educacionales, cultura escolar, modelo de competencias, crisis de la educación, desencantamiento de la educación, epistemología de la educación.

\section{INTRODUÇÃO}

No momento em que escrevemos, a maioria dos institutos e departamentos de Educação - senão todos - tem seus próprios esquemas e programas de estudo de Políticas Educacionais, dentro de um quadro geral dos princípios e das práticas educacionais. O leitor notará que, em nosso exame político, este texto tem como objetivo analisar o discurso da crise da educação: do modelo de competências à epistemologia da educação, e do discurso que propaga a necessidade da escola, e da educação, adequar-se às mudanças culturais e tecnológicas, a partir da década de 1980, no contexto da Mundialização do Capital, que configuraram o mundo produtivo com algumas características tendenciais: flexibilização da produção e reestruturação das ocupações nas organizações; integração de setores da produção; multifuncionalidade, adaptabilidade e polivalência dos trabalhadores; valorização dos saberes dos trabalhadores não ligados ao trabalho prescrito ou ao conhecimento formalizado ou institucionalizado.

O objetivo deste artigo é analisar como as mudanças do mundo do trabalho, no processo da reestruturação produtiva, interferiram nas políticas públicas para a educação, mais particularmente no que se conhece como a pedagogia das competências, refletindo num desencantamento com a Educação, principalmente na sua forma institucionalizada, o que pode ser percebido tanto no discurso daqueles envolvidos nas práticas quanto na sociedade em geral. Numa perspectiva que aborda o desencantamento do mundo no sentido weberiano, percebe-se, paralelamente a este, um encantamento com a concepção neoliberal de mundo que, no entanto, desumaniza-o. 
Segundo Mark Blaug 3 , há uma nítida analogia entre a produtividade física do capital e a Educação, justificando-se o tratamento analítico desta como capital, isto é, capital humano, uma vez que se torna parte da pessoa que a recebe, num sentido hedonista. Ademais, a Educação enquanto investimento obedece uma opção racional entre custos atuais e renda futura, no contexto mais amplo da maximização dos retornos individuais ou sociais. No contexto dessas transformações, estudos sociológicos e pedagógicos recuperam o debate sobre a educação, ao mesmo tempo em que se testemunha a emergência da noção de competência atendendo a diversos propósitos: reordenar conceitualmente e epistemologicamente a compreensão da relação trabalho/educação, desvirtuando o espaço das ocupações/empregos e institucionalizar novas formas de educar/ formar os trabalhadores e submetê-los internamente às organizações e no mercado de trabalho em geral, sob novas identidades profissionais. Diante do exposto, perguntamos: que alterações a reorganização econômica confere à esfera educacional? Por que nossa Educação atravessa uma crise? Obviamente, a construção do conhecimento implica em algo mais que a simples assimilação dos valores dominantes na sociedade.

No mundo atual, o aspecto instrucional da educação já não consegue dar conta da profusão de conhecimentos disponíveis e emergentes mesmo em áreas específicas do conhecimento. Por isso, esta não deveria preocupar-se tanto com os saberes instrumentais, privilegiando a capacidade de acessá-los, decodificá-los e manejá-los. O aspecto instrucional deveria estar em função da emergência do aprender, na emergência da substituição da pedagogia das competências e dos saberes pré-fixados por uma pedagogia da pergunta, do melhoramento das perguntas, do encantamento. O reencantamento da educação requer a união entre sensibilidade social e eficiência pedagógica. Portanto, o compromisso ético-político do/a educador/a deve manifestarse primordialmente na excelência pedagógica e na colaboração do próprio contexto escolar.

Assim, desejamos elaborar crítica ao pensamento pós-moderno apresentando-o como expressão ideológica da produção material dessa crise, demonstrando criticamente suas reflexões e seu impacto ideológico na Educação a partir do referencial teórico marxista.

3 Mark Blaug, Introdução à economia da educação (Porto Alegre: Globo, 1975), 21. 
$\mathrm{O}$ resultado da pesquisa demonstra que a crise da educação e a pedagogia das competências expressam o movimento e os interesses do capital contemporâneo na sua crise estrutural. A determinação do capitalismo tardio sobre a educação foi vista por meio da influência da terceira revolução tecnológica, partindo do pensamento deHugo Assmann, no desencantamento da educação.

\section{As reformas educacionais e a crise da educação sob a perspectiva do modelo de competências}

A hipótese geral construída e apresentada para sustentar o discurso de crise da educação se deve ao fato de que a educação não realizou sua imediata adesão aos fundamentos propostos pela reforma da educação promovida na década de 90, e início da primeira década do século XXI, ocorridas no âmbito do capitalismo global, e de sua apropriação do chamado modelo de competências.

O contexto que orienta esse texto são as mudanças nos processos normativos que marcaram a educação brasileira a partir da década de 1990. Nesse período uma série de políticas públicas foi produzida tendo como objetivo a realização de reformas que, no discurso do Ministério da Educação, de empresários e de setores importantes da academia, criariam as condições para adequar o sistema de ensino às novas demandas oriundas dos processos de trabalho. Assim, a lógica de uma educação instrumental e adaptativa já se mostrava de forma consistente nos discursos iniciais e se tornaria um elemento mais visível na medida em que as intenções de reforma se materializavam em políticas públicas.

Nos últimos 30 do século XX uma profunda crise assola o capitalismo, com profundas consequências para as relações entre capital e trabalho, notadamente o desemprego estrutural, a precarização do trabalho, as mudanças nos processos de trabalho, etc. Vivíamos um fim de milênio repleto de transformações e rupturas que afetaram, ainda que de modo desigual, todas as experiências humanas.

Nicolau Sevcenko afirma que o que distinguiu particularmente o século XX foi uma tendência contínua, acelerada e flexível de mudança tecnológica, 
com efeitos multiplicativos e revolucionários sobre praticamente todos os campos da experiência filosófica, científica e artística humana:

Esse surto de transformações constantes pode ser dividido em dois períodos básicos, intercalados, pela irrupção e transcurso da Segunda Guerra Mundial. Na primeira dessas fases, prevaleceu um padrão industrial que representava o desdobramento das características introduzidas pela revolução Científico Tecnológica de fins do século XIX [...] A segunda fase, iniciada após a guerra, foi marcada ela intensificação das mudanças imprimindo à base tecnológica um impacto revelado sobretudo pelo crescimento dos setores de serviços de comunicações $e$ informações - o, que levou a ser caracterizado como período pós-industrial. ${ }^{4}$

Segundo Castells, ${ }^{5}$ a nova ordem internacional, ainda em curso e transição, apontou para diversas direções, como a multipolaridade, composta de novos pólos de poder econômico e político e a unilateralidade da hegemonia dos Estados Unidos, a maior potência econômica e militar no final do século XX.

A nova ordem não surgiu de repente e suas origens podem ser encontradas no pós-guerra, principalmente na segunda metade do século XX. Ainda segundo Castells, um novo mundo está tomando forma no começo do atual milênio. David Harvey, ${ }^{6}$ no que diz respeito à situação mundial contemporânea, ressalta dramaticamente a intensidade da crise estrutural global do capitalismo, desde a década de 1970. Ao contrário das crises anteriores, que foram parciais e localizáveis, parece que, pela primeira vez, o capitalismo foi abalado em suas bases como sistema mundial. Contrastando com situações passadas, o caráter visivelmente global da crise sócio-econômica necessita de soluções globais para os problemas do nosso tempo.

As tendências que se apresentam ao mundo do trabalho, chamadas genericamente de reestruturação produtiva, são decorrentes da profunda crise que assola o capitalismo nesse período e que se materializa em processos

\footnotetext{
Nicolau Sevcenko, A corrida para o século XXI: no Loop da Montanha Russa (São Paulo: Companhia das Letras, 2001), $23-24$.

Manuel Castells, A Era da informação: economia, sociedade e cultura (São Paulo: Paz e terra, 1999).

David Harvey, Condição pós-moderna (São Paulo: Loyola, 2004).
} 
como a chamada revolução científico-tecnológica, a crise ${ }^{7}$ do petróleo da segunda metade da década de 1970, a destruição das políticas de BemEstar Social na Europa, os processos de privatização e desregulamentação econômica e o aprofundamento de uma série de legislações que vão criar as condições para a precarização do trabalho.

As inovações na estrutura produtiva, tais como informatização e robotização, e suas consequências na organização e relações de trabalho como, por exemplo, o aumento do desemprego estrutural, o aumento da subproletarização, a expansão do setor de serviços e a desregulamentação dos direitos trabalhistas, constituem-se para o capital, em mecanismos de superação da crise.

Essa crise provocou a elevação dos indicadores de pobreza, miséria e violência no mundo. Para Neise Deluiz, as razões da crise estrutural que se configura nos países centrais a partir da década de 1960 se expressam:

1. Pelo esgotamento do padrão de acumulação taylorista / fordista;

2. Pela hipertrofia da esfera financeira na nova fase do processo de internacionalização do capital;

3. Por uma acirrada concorrência intercapitalista, com tendência crescente à concentração de capitais devido às fusões entre empresas monopolistas e oligopolistas;

4. Desregulamentação dos mercados e da força de trabalho, resultantes da crise da organização assalariada do trabalho e do contrato social. ${ }^{8}$

As transformações trouxeram um conjunto de mudanças dimensionadas pelas reestruturações empreendidas no processo produtivo por meio da constituição das formas de produção flexíveis ${ }^{9}$, da inovação cientifico -

7 Os anos 1970, uma década de crise e recessão na economia mundial, assinalaram o esgotamento do modelo de crescimento adotado no pós-guerra, encerrando um longo ciclo ascendente da economia capitalista. A crise dos anos 1970 ficou conhecida nos meios de comunicação como "crise do petróleo". Efetivamente, a década conheceu dois grandes choques altistas do preço do principal combustível das economias industriais, que passou de menos de dois dólares o barril para quase trinta dólares durante o período. Indiscutivelmente, o choque do petróleo foi um componente essencial da "crise dos 70", atuando como poderoso acelerador da inflação nas economias desenvolvidas. Contudo, o petróleo não pode ser visto como causa de uma crise de natureza estrutural, que já se manifestava antes da primeira alta do preço do barril e que era condicionada pela completa alteração das condições gerais que tinham impulsionado o ciclo ascendente das décadas de 1950 e 1960.

8 Neise Deluiz, O Modelo das Competências Profissionais no Mundo do Trabalho e na Educação: Implicações para o Currículo (Rio de Janeiro: SENAC, 2001).

9 A economia flexível é marcada por um confronto direto com a rigidez do "fordismo". Ela se apóia na flexibilidade dos processos de trabalho, dos mercados de trabalho, dos produtos e padrões de consumo. Caracteriza-se pelo surgimento de setores de 
tecnológica aplicada aos processos produtivos, dos novos modelos de gerenciamento da organização do trabalho.

Para Harvey:

O padrão de acumulação flexível é caracterizado, por setores da produção inteiramente renovados, por diferentes maneiras de fornecimento de serviços financeiros, novos mercados e, sobretudo, por taxas altamente intensificadas de inovações comercial, tecnológica e de organização, sendo marcada, portanto, por um confronto com a rigidez do 'fordismo'. ${ }^{10}$

Nesse sentido, François Chesnais ${ }^{11}$ afirma que as políticas de liberalização, desregulamentação e privatização que os Estados capitalistas adotaram a partir de 1978 ampliaram a liberdade de o capital mover-se em escala internacional. Chesnais considera mais adequado denominar o processo atual de mundialização do capital, pois ele representa o próprio regime de acumulação do capital. Afirma que, em primeiro lugar, globalização é dada não pela mundialização das trocas, mas pela mundialização das operações do capital, em suas formas tanto industriais quanto financeiras. Em segundo lugar, nas primeiras etapas do ciclo de acumulação, o capital coloca em movimento um grande volume de mercadorias, mas, contraditoriamente, esse mesmo capital busca libertar-se da forma mercadoria, através do predomínio de mecanismos financeiros que possibilitem a acumulação ampliada do capital.

Para Chesnais, ${ }^{12}$ a partir de 1978, a burguesia mundial, conduzida pelos Estados Unidos e pela Inglaterra, começa a desmantelar as instituições e estatutos que materializavam o estado anterior das relações. As políticas de liberação, desregulamentação e privatização surgiram como alternativa para que o capital reconquistasse a liberdade que havia perdido a partir de 1914.

produção inteiramente novos, novas maneiras de fornecimento de serviços financeiros, novos mercados e, sobretudo, taxas altamente intensificadas de inovação comercial, tecnológica e organizacional. A acumulação flexível envolve rápidas mudanças dos padrões do desenvolvimento desigual, tanto entre setores como entre regiões geográficas, criando, por exemplo, um vasto movimento no emprego no chamado "setor de serviços", bem como conjuntos industriais completamente novos em regiões até então subdesenvolvidas. (Harvey, 2004, p. 140).

10 David Harvey, Condição pós-moderna (São Paulo: Loyola, 2004), 143.

11 François Chesnais, A mundialização do capital (São Paulo: Xamã, 1996).

12 François Chesnais, A mundialização do capital (São Paulo: Xamã, 1996), 15. 
$\mathrm{Na}$ verdade, segundo Chesnais ${ }^{13}$ esse processo firmou e consolidou a mundialização como um regime institucional internacional do capital concentrado e conduziu a um novo salto na polarização da riqueza, corroborando e acentuando com a evolução dos sistemas políticos rumo à dominação das oligarquias obcecadas pelo enriquecimento e voltadas completamente para a reprodução da sua dominação. Portanto, o neoliberalismo amplia o poder de acumulação de capitais pelas classes dominantes.

Podemos então afirmar que as mudanças na organização de produção, bem como a liberdade de o capital mover-se em escala planetária, é muito mais que apenas uma nova forma de gerenciar a produção, representando assim uma nova forma de configuração societária, preservando o status quo. Assim, a produção flexível pode ser considerada uma maneira de conter a onda de insatisfaç1sórias), sem, portanto, uma ampla participação parlamentar e da sociedade civil.

Exemplo concreto dessa dualidade entre discurso ideológico e coação normativa é o processo de elaboração da nov ${ }^{14}$ Lei de Diretrizes e Bases da Educação - LDB n ${ }^{\circ}$ 9.394/96. Neste sentido a educação foi objeto de intensas mudanças, seja na sua organização, seja na concepção curricular modificando em muito o perfil, a estrutura e os objetivos da educação.

Na chamada sociedade pós-moderna flexibilidade e instabilidade do emprego são constantes. A incorporação da tecnologia da informação e a constante evolução tecnológica alteraram a forma de acumular capital. O crescimento acelerado do setor de serviços, o aumento do número de mulheres no mercado de trabalho, o aumento estrutural do desemprego, e o surgimento de novas formas de gestão industrial são característicos desse processo. Além disso, torna-se cada vez mais comum o uso de palavras do campo empresarial, nos planos e projetos pedagógicos, como: produtividade, eficiência, gerência, clientes, gestão por metas, dentre outras. Todo

13 François Chesnais, A mundialização do capital (São Paulo: Xamã, 1996), 20.

14 O processo de tramitação da nova LDB inicia-se na Câmara Federal em dezembro de 1998, dois meses após a promulgação da nova Constituição Federal. O Deputado Octavio Elísio (PMDB) apresentou o primeiro projeto. Em março de 1989, o Deputado Ubiratan Aguiar então presidente da Comissão de Educação, Cultura e Desporto, organiza um Grupo de Trabalho do qual o Deputado Florestan Fernandes é coordenador geral e o Deputado Jorge Hage o relator. Paralelo a esse processo ocorre à tramitação de um novo projeto no Senado, no início da década de 1990, elaborado por Darcy Ribeiro (PDT-RJ) e pelos senadores Marco Maciel (PFL - atual DEM - PE) e Maurício Correa (PDT-DF), que estava mais afinado com os interesses do Governo de Fernando Henrique Cardoso. Se no primeiro caso houve ampla participação da sociedade, o mesmo não ocorreu com o projeto do Senado. 
esse vocabulário é apresentado dentro de uma rede ideológica tecida para a reprodução do capitalismo flexível, afetando a escola, a universidade, seus alunos e professores.

Pablo Gentili ${ }^{15}$ explica que foi a ideologia do toyotismo, mais precisamente nas décadas de 1980 e 1990, que promoveu o deslocamento da ênfase do papel da escola como locus de formação para o emprego, fortalecendo o papel econômico da educação para a competitividade das economias globalizadas. O predomínio de padrões flexíveis (toyotismo) em detrimento de procedimentos rígidos (taylorismo e fordismo) tem produzido uma demanda para o desenvolvimento de habilidades cognitivas e comportamentais, supostamente capazes de garantir a empregabilidade, como por exemplo: rapidez de respostas, criatividade, capacidade para trabalhar em grupo, resistência a pressões, dentre outras.

O conceito de empregabilidade passa a ser utilizado como mecanismo que retira do capital e do Estado a responsabilidade pela implementação de medidas capazes de garantir um mínimo de condições de sobrevivência para a população. Para os ideólogos da acumulação flexível a educação deve ser funcional ao capital, como qualquer outro tipo de mercadoria. Essa perspectiva dilui o sujeito, a razão, a história e a totalidade na lógica do capital. $\mathrm{Na}$ ausência de novos ideais e de projetos históricos e sociais se impõe o consumismo e os valores de trocas, símbolo e verdades universais e absolutas. Com isso, a racionalidade neoliberal, articulada à justificativa de uma economia flexível, influi cada vez mais, na suposta necessidade de a escola subordinar-se às demandas do setor produtivo. ${ }^{16}$

Ao pensar a escola sob a ótica empresarial, a educação passa a ser defendida como um requisito fundamental para o desenvolvimento econômico e para o progresso material dos indivíduos cuja base dessa forma de pensar a educação é a teoria do capital humano, ${ }^{17}$ formulada no inicio dos anos 1960.

15 Pablo Gentili, Educar para o desemprego: a desintegração da promessa integradora (Petrópolis: Vozes, 2002).

16 Maria Auxiliadora Monteiro Oliveira, Políticas públicas pra o ensino profissional: o processo de desmantelamento dos CEFETs (Campinas: Papirus, 2003)

17 A teoria do capital humano afirma que "uma educação adicional elevará os rendimentos futuros, e, neste sentido, a aquisição de educação é da natureza de um investimento privado em rendimentos futuros” (Blaug, 1971, p.21). Assim, há uma nítida analogia entre a produtividade física do capital e a educação, justificando-se o trata-mento analítico da educação como capital, isto é, capital humano, posto que se torna parte da pessoa que a recebe. A principal hipótese que está subjacente a este tratamento da educação é a de que alguns aumentos importantes na renda nacional são uma conseqüência de adições a esta forma de capital.. Ademais, a educação, enquanto investimento, obedece a uma opção racional entre custos atuais e renda futura, no contexto mais amplo da maximização dos retornos individuais ou sociais. Logo, a distribuição da educação corresponde à distribuição das preferências, a qual é considerada uma variável exogenamente determinada, se bem que de alguma maneira influenciada pelo 
A partir daqui deve-se chamar a atenção para o fato de que estes documentos discutidos até aqui incorporaram conceitos do mundo produtivo e do âmbito do trabalho, como é de fato visível a partir da análise do modelo das Competências na educação. Isso se deve, pelo fato de que o conhecimento adquiriu novos papéis, sobretudo, a partir de sua inclinação aos interesses do mundo produtivo.

Nessa perspectiva o modelo das competências é deslocado do universo produtivo, do âmbito dos negócios e lançado sobre a educação. Cabe desenvolver uma análise mais atenta desse conceito. Segundo o Novo Dicionário Aurélio da Língua Portuguesa (2004, p. 508) por competência entende-se:

1. Faculdade concedida por lei a um funcionário, Juiz do Tribunal para apreciar e julgar certos pleitos e questões. 2. Qualidade de quem é capaz de apreciar ou resolver certo assunto, fazer determinada coisa; capacidade habilidade, aptidão, idoneidade. 3. Oposição, conflito, luta..$^{18}$

Observa-se assim, que competência é uma palavra do senso comum, utilizada para designar uma pessoa qualificada para realizar alguma coisa bem feita, ou realizada corretamente. Nos últimos anos, o conceito de competência entrou para a pauta das discussões acadêmicas e empresariais, associado a diferentes finalidades. Para Fernando Fidalgo:

A competência passou a ser instituída a partir da década de 80, com o processo de reestruturação produtiva instaurado como forma de resposta à crise do trabalho prescrito, evidenciada neste período. Trata-se de uma noção, pois ainda não se constituiu como uma definição instituída de forma a referenciá-la como conceito formal. ${ }^{19}$

Perrenoud observa que competência é a faculdade de mobilizar um conjunto de recursos cognitivos (saberes, capacidades, informações etc.) para solucionar com pertinência e eficácia uma série de situações. Nessa perspectiva, o autor se utiliza de quatro aspectos para realizar a insistência da noção de competência:

progressivo melhoramento do padrão de vida.

18 Aurélio Buarque Holanda, Dicionário da Língua Portuguesa (São Paulo: Moderna, 2010), 508.

19 Fernando Fidalgo, Educação Profissional e a lógica das competências (Petrópolis: Vozes, 2007), 19. 
1) As competências não são elas mesmas saberes, savoir-faire ou atitudes, mas mobilizam, integram e orquestram tais recursos.

2) Essa mobilização só é pertinente em situação, sendo cada situação singular, mesmo que se possa tratá-la em analogia com outras, já encontradas.

3) O exercício da Competência passa por operações mentais complexas, subentendidas por esquemas de pensamentos, que permitem determinar (mais ou menos consciente e rapidamente) e realizar (de modo mais ou menos eficaz) uma ação relativamente adaptada à situação.

4) As competências profissionais constroem-se, em formação, mais também ao sabor da navegação diária de um professor, de uma situação de trabalho a outra. ${ }^{20}$

Nesse sentido, para Perrenoud, competência é aquilo que permite enfrentar um tipo de tarefas e situações, apelando para noções, conhecimentos, métodos e técnicas. A competência é um saber mobilizar situações a fim de solucionar um problema.

Para Guiomar Nano Mello, ${ }^{21}$ competência é a capacidade de mobilizar conhecimentos, valores e decisões para agir de modo pertinente numa determinada situação. Portanto, para constatá-la, há que considerar também os conhecimentos e valores que estão na pessoa e nem sempre podem ser observados. Ainda de acordo com a autora, a competência só pode ser constituída na prática. Defende ainda, que a competência pressupõe não só o saber, mas o saber fazer. Aprende-se fazendo, numa situação que requeira esse fazer determinado.

Ferretti critica o conceito de competências, afirmando que este sofre um deslocamento do campo dos negócios, o que por si só, já é indicativo de que as reformas promovidas na educação, contrariamente afirmado pelos discursos oficiais, tende a privilegiar os interesses de um setor social e não os da sociedade como um todo. Trata-se de um conceito que pode ser entendido no âmbito da Sociologia do trabalho e da educação, preconizando a adequação da educação à nova organização do trabalho necessária ao

20 Philippe Perrenoud, Dez novas competências para ensinar (Porto Alegre: Artmed, 2000), 15.

21 Guiomar Nano Mello, Cidadania e competitividade: desafios educacionais do terceiro milênio (São Paulo: Cortez, 2002). 
enfrentamento da crise do capital.

Baseado nisso afirma que a competência seria entendida, nesse quadro, como a capacidade de mobilizar saberes de diversa natureza (o saber propriamente dito, ou seja, o conhecimento; o saber-fazer, ou seja, a capacidade de ampliar conhecimentos; e, finalmente, o saber ser, ou seja, a capacidade de relacionarse afetiva e socialmente e ter a disponibilidade afetivo-social para acionar todos esses saberes, tendo em vista a realização de uma atividade que requeira sua utilização). ${ }^{22}$

O modelo das competências, quando deslocado para o universo pedagógico, pode ser representado por um saber agir responsável e reconhecido, que implica mobilizar, integrar, transferir conhecimentos, recursos e habilidades, que agreguem valor econômico à organização e valor social ao indivíduo, em detrimento das ações coletivas, subordinando aos mecanismos do mercado.

Segundo Deluiz, no modelo das competências algumas indicações gerais são propostas para a organização do currículo: “A discussão sobre o enfoque das competências invade o mundo da educação no quadro de questionamentos feitos ao sistema educacional diante das exigências de competitividade, produtividade e de inovação do sistema produtivo". ${ }^{23}$

Considerando a noção de competência como multidimensional, envolvendo elementos que vão do individual ao sociocultural, situacional (contextual - organizacional) e processual ${ }^{24} \mathrm{com}$ as quais os alunos possam assimilar informações e saber utilizá-las em contextos pertinentes, pois os conteúdos curriculares são instrumentos a serviço da construção de competências, habilidades e disposições de conduta. O fato é que o modelo das Competências, que enfatiza os procedimentos cognitivos, tais como, aprender a aprender, aprender a fazer, aprender a ser, adquiriu relevância e centralidade no debate educacional contemporâneo.

22 Celso João Ferretti, A reforma do Ensino Médio: uma crítica em três níveis (São Paulo: UNESP, 2003).

23 Neise Deluiz, O Modelo das Competências Profissionais no Mundo do Trabalho e na Educação: Implicações para o Currículo (Rio de Janeiro: SENAC, 2001), 52.

24 A visão construtivista do MEC/SEMTEC sofre a influência das concepções de Perrenoud, para o qual a competência... "situase além dos conhecimentos. Não se forma com a assimilação de conhecimentos suplementares gerais ou locais, mas sim com construção de um conjunto de disposições e esquemas que permitem mobilizar os conhecimentos na situação, no momento certo e com discernimento". (Perrenoud, 1999), 31. Para o autor, a competência "orquestra um conjunto de esquemas. Um esquema é uma totalidade constituída, que sustenta uma ação ou operação única, enquanto uma competência com uma certa complexidade envolve diversos esquemas de percepção, pensamento, avaliação e ação, que suportam inferências, antecipações, transposições analógicas, generalizações, formação de decisões, etc”. (Perrenoud, 1999). 24 
Em face da nova proposta de investir na capacidade de aprendizagem, no desenvolvimento de maneiras próprias de pensar e de tomar decisões, na relação do indivíduo consigo mesmo e com a sociedade, as diretrizes curriculares, produtos da nova educação brasileira expressam um "novo paradigma curricular", no qual trabalho e cidadania estão presentes em todos os momentos.

Assim, a lógica de uma educação instrumental e adaptativa já se mostrava de forma consistente nos discursos iniciais e se tornaria um elemento mais visível na medida em que as intenções de reforma se materializavam em políticas públicas com o modelo de competências, contrária, portanto a visão de que a educação é um processo por meio do qual os indivíduos assemelhamse e diferenciam-se. Por meio dela tornam-se iguais, próximos, mas tornam-se também diferentes uns dos outros. Nesse sentido a educação é o movimento que permite a homens e mulheres apropriarem-se da cultura, estabelecendo com ela uma identidade. Tal movimento atribui à educação uma dimensão de realização social, e outra, subjetiva, de realização individual.

\section{A crise da educação sob a perspectiva do desencantamento do mundo}

A realidade educacional brasileira reflete um desencantamento com a educação, principalmente na sua forma institucionalizada, que pode ser percebido tanto no discurso daqueles envolvidos nas práticas escolares, gestores, professores, alunos e seus familiares, quanto na sociedade em geral. Numa perspectiva que aborda o desencantamento do mundo no sentido weberiano, percebe-se paralelamente a este, um encantamento com a concepção neoliberal de mundo que, no entanto, desumaniza.

Ao questionar se seria possível analisar e compreender o desencantamento da educação a partir da inseparável relação entre a cultura social e a cultura escolar, busca-se esclarecer o aparente paradoxo de um encantamento que desencanta.

O conceito de desencantamento do mundo se aproxima dos temas da perda de sentido da vida e do racionalismo. A construção deste conceito aparece com o interesse de encontrar a origem da atitude moderna de racionalização e 
da secularização. O desencantamento do mundo consiste na desmistificação, na perda dos aspectos e das explicações mágicas para a vida, de forma que a religião perde o caráter de organizadora de todos os aspectos da vida e de fornecedora do seu sentido.

Desta forma, o desencantamento do mundo produz a separação entre as diferentes esferas da vida cotidiana. A esfera econômica ganha uma legalidade própria que não mais depende da legitimação religiosa. $\mathrm{O}$ mesmo processo ocorre com as demais esferas, e cada uma delas ganha sua própria legalidade, passando a orientar-se por princípios que são autoreferenciados. O desencantamento do mundo, em Weber, resulta na antítese em as diferentes esferas:

Vista dessa forma, a 'cultura' surge como a emancipação do homem em relação ao ciclo da vida natural, organicamente prescrito. Por essa razão mesma, cada passo à frente da cultura parece condenado a levar a um absurdo ainda mais devastador. O progresso dos valores culturais, porém, parece tornar-se uma agitação insensata a serviço de finalidades indignas e, ainda mais, autocontraditórias e mutuamente antagônicas. O progresso dos valores culturais parece ainda mais insensato quanto mais ele é tomado como uma tarefa sagrada, uma 'vocação'. [...] A toda construção de natureza específica de cada esfera especial existente no mundo, esse conflito parece destacar-se cada vez mais e de forma mais insolúvel. [...] E não só o pensamento teórico, desencantando o mundo, que levava a essa situação, mas também a própria tentativa da ética religiosa de racionalizar prática e eticamente o mundo..$^{25}$

A perda de liberdade, refletida pela dominação, é outro aspecto negativo que acompanha o processo de desencantamento do mundo, uma vez que a renúncia do mundo convive com o domínio do mesmo. Trata-se da combinação puritana entre restrição ao consumo e a liberação para o acúmulo racional da riqueza. Esta nova atitude contribuiu para a formação da moderna ordem econômica. A dominação sobre o mundo, paradoxalmente, exercida pelo puritano volta-se contra ele mesmo. O desencantamento do mundo acaba por lançar o homem numa realidade sem sentido e sem liberdade.

Todavia, estudos mais recentes na área das ciências sociais têm

25 Max Weber, Rejeições religiosas do mundo e suas direções (Rio de Janeiro: Guanabara Koogan, 1982), 407-408. 
demonstrado a impossibilidade, para os seres humanos, de se viver num mundo totalmente desencantado ${ }^{26}$. A grande explosão de manifestações e práticas religiosas, por exemplo, é um aspecto disso. Essas manifestações não têm a característica de relacionar as diferentes esferas da vida. De igual forma, alguns estudos mostram o caráter encantador da cultura neoliberal, provada, de certa forma, pelos processos de globalização.

Pode-se dizer que o mundo atualmente é encantado pela cultura do consumo, uma vez que essa cultura tem influenciado cada vez mais as formulações sobre o sentido da vida. Porém, esse encantamento, devido ao caráter sedutor e motivador da cultura do consumo, não logra formular um sentido de vida que articule as diferentes esferas da vida, mas, ao contrário, busca impor a sua lógica interna auto-legitimada - formulada em princípios econômico-financeiros - às outras esferas.

O processo de mundialização, que decorre da necessidade de expansão do capitalismo em sua vertente neoliberal na pós-modernidade, cria a sua própria lógica interna que legitima de forma inquestionável e acrítica a aceitação do fetichismo do consumo. Ou seja, a busca constante pela acumulação de riqueza e ostentação de bens de consumo encanta, permeando a significação e o sentido das práticas sociais.

Esse sentido legitima a expectativa socialmente aceita do imediatismo e utilitarismo nas mais diversas dimensões das práticas sociais, inclusive da educação, ao trazer para esta a idéia de que a função da escolarização é formar indivíduos capacitados para ocupar posições de trabalho na sociedade que lhe permitam acumular riquezas e aumentar o seu poder de consumo.

\section{Crítica desde a epistemologia da educação}

Entender a educação como a possível solução para a atual crise social em que se vive na pós-modernidade significa ignorar que a educação é a um só tempo produtora e produto de cultura. A cultura social é produzida e reproduzida na dinâmica de um processo histórico-dialético de práticas sociais que se dão em diversas esferas, inclusive no cotidiano das práticas escolares. Entendese aqui por cultura social o conjunto das culturas específicas criadas pelo

26 Destacamos principalmente os trabalhos de Hugo Assmann e Jung Mo Sung indicados na bibliografia. 
homem e que possibilitam e regulam a vida em sociedade.

Em geral, os conceitos de educação e escolarização se confundem no senso comum, e desta forma, os princípios e fins da escola não são explicitados de modo objetivo. O conceito amplo de educação não é mais entendido como um processo que ocorre nos diferentes espaços de socialização, como por exemplo na família, nas instituições religiosas, no trabalho, entre outros processos informais. Passa-se a entender que a educação ocorre apenas em sua forma institucionalizada, sendo esta tarefa da escola.

Ao falhar nesta inexequível tarefa, a escola é desqualificada em sua função social e se atribui a ela tanto a causa quanto a manutenção de uma crise educacional. Neste sentido, é como se a escola estive fora de um contexto social mais amplo e fosse responsável pelo que se dá tanto no seu interior quanto no seu entorno. Em partes, a crise atribuída à organização escolar e à qualidade do ensino formal decorre de uma crise social orgânica mais ampla e geral da civilização moderna.

A instituição escolar tem sua origem nos princípios liberais que marcaram o processo histórico de formação do Estado Burguês. Em linhas gerais, os ideais liberais caracterizavam a concepção da escola pública como: laica, sem a implicação de ser neutra; universal, no sentido de reforçar a idéia de igualdade; gratuita, enquanto dever do Estado, porém com possibilidade da existência de um sistema privado de ensino ao afirmar a liberdade pedagógica para educar e ser educado; e obrigatória, possibilitando a formação de mãode-obra necessária ao desenvolvimento industrial e à difusão de uma visão de mundo.

A educação institucionalizada, especialmente nos últimos 150 anos, serviu - no seu todo - ao propósito de não só fornecer os conhecimentos e o pessoal necessário à maquina produtiva em expansão do sistema do capital, como também gerar e transmitir um quadro de valores que legitima os interesses dominantes, como se não pudesse haver nenhuma alternativa à gestão da sociedade, seja na forma "internalizada" (isto é, pelos indivíduos devidamente "educados" e aceitos) ou através de uma dominação estrutural e uma subordinação hierárquica e implacavelmente impostas. ${ }^{27}$

O processo de escolarização organiza procedimentos e políticas de ensino

27 István Mészáros, A educação para além do capital (São Paulo: Boitempo Editorial, 2005), 35.

Rev. hist.edu.latinoam - Vol. 15 No. 21, julio-diciembre 2013 - ISSN: 0122-7238 - 283 - 304. 
de maneira tal que a escola, por meio de suas práticas no cotidiano, articula os sentidos e significados dos modos de socialização que dissemina. Em outras palavras, a escolarização, ou o ensino formal, difunde e reafirma uma cultura socialmente dada, mas não sem que esta cultura seja apropriada e re-significada por docentes e discentes, indivíduos estes, marcados por uma história concreta e particular.

O sistema de produção capitalista do Estado moderno se operacionaliza dentro de uma lógica destrutiva, desumanizante, que acentua as desigualdades sociais ao evidenciar contradições e disparidades entre o desperdício e a escassez, a riqueza e a miséria, a civilização e a barbárie.

Em outras palavras, o ideal neoliberal supervaloriza o individualismo, a liberdade e uma suposta igualdade, alienando o indivíduo que não toma consciência da sua relação genérica com os outros enquanto ser humano. $\mathrm{O}$ atraente apelo humanista e universalista do discurso neoliberal, ao encantar, esconde o grau de alienação de uma sociedade.

Os processos de homogeneização que atenderiam a esse conceito de igualdade não conseguem superar a individualidade das histórias de vida dos alunos ou tão pouco igualizar os processos de apropriação e objetivação das formas de regulação impostas pela escola.

Neste sentido, as expectativas de professores, pais e alunos sobre o que deveria ser a escola se frustram, gerando inevitáveis conflitos e tensões no campo educacional. Sem um entendimento claro das relações dialéticas entre teoria e prática, professor e aluno, ensinar e aprender, senso comum e conhecimento filosófico, ou das influências ideológicas a que a sociedade está submetida, se estabelece um jogo de culpas para tentar justificar a origem dos problemas educacionais.

Ao apontar para a relação entre o fetichismo do consumo e o desencanto com a educação e com a escola, em virtude desta não servir ao imediatismo e ao utilitarismo do desejo, justificado e legitimado pelo sistema capitalista, de acumulação de riquezas e de consumo, procuramos demonstrar que " $\mathrm{O}$ desencanto se expressa na perda do sentido próprio do processo educacional, 
que vai sendo reduzido cada vez mais ao critério econômico-fincanceiro" ${ }^{28}$. Nossa crítica parte da necessidade de se discutir a crise da educação a partir da epistemologia da educação, ao invés de reduzir a discussão às expectativas criadas pelo modelo de competências. Segundo Severino (2009), não devemos fugir do enfrentamento dos desafios epistemológicos da educação.

Impõe-se considerar preliminarmente, a exigência do compromisso do conhecimento com a relevância social. A legitimação de todos os processos e procedimentos relacionados com a educação está necessariamente vinculada aos valores e aos objetivos relacionados com a construção de uma sociedade onde as pessoas possam encontrar subsídios para sua emancipação [...]. O segundo pressuposto é a concepção do conhecimento como um processo subjetivo de construção dos conteúdos objetivos. Epistemologicamente falando [...] o processo de ensino/aprendizagem se constitui substantivamente como um processo construcional de conhecimento. [...] Construir o objeto do conhecimento é apreendê-lo em suas próprias fontes, em sua particularidade: não é contemplá-lo ou intuí-lo em sua essência, nem representá-lo abstratamente; ou melhor, a sua representação abstrata não é um ponto de partida, é um ponto de chegada, é o resultado de uma construção feita com os dados e elementos fornecidos pela fonte na qual o objeto se realiza concretamente. ${ }^{29}$

\section{CONCLUINDO}

Obviamente a construção do conhecimento implica em algo mais que a simples assimilação dos valores dominantes na sociedade. Grande parte do debate sobre a crise da educação para reduzir a questão à falta de competência em assimilar as exigências impostas pela produção capitalista de recorte neoliberal. Nesse sentido, entende-se a missão da educação a partir do compromisso de manutenção do status quo. Isto é, não se considera a educação a partir de sua própria epistemologia, mas a partir de sua funcionalidade em atender os interesses da classe dominante. Paulo Freire compreendeu que esse tipo de educação é resultado de um processo de alienação, e atua como perpetuadora da alienação. Em outras palavras, a educação, epistemologicamente, torna-se impossível. Desta forma, Freire

28 Jung Sung Mo, Educar para reencantar a vida (Petrópolis: Vozes, 2006), 83.

29 Antônio Joaquim Severino. "Premissas e desafios da pesquisa na pós-graduação em educação: da relevância social ao cuidado epistemológico". Perspectivas atuais da pesquisa em educação. Leandro de Proença-Lopes [et al]. Anais do III Encontro de Pesquisa Discente do Programa de Pós-Graduação em Educação da UNINOVE. (São Paulo: PPGE/UNINOVE, 2009 ), 2. 
define a educação como prática de liberdade. Tal educação deve problematizar os pressupostos dominantes da sociedade na qual ela acontece:

[A educação] problematizadora parte exatamente do caráter histórico e historicidade dos homens. Por isto mesmo é que os reconhece como seres que estão sendo, como seres inacabados, inconclusos, em e com uma realidade que, sendo histórica também, é igualmente inacabada. Na verdade, diferentemente dos outros animais, que são apenas inacabados, mas não são históricos, os homens se sabem inacabados. Têm a consciência de sua inconclusão. Aí se encontram as raízes da educação mesma, como manifestação exclusivamente humana. Isto é, na inconclusão dos homens e na consciência que dela têm. Daí que seja a educação um quefazer permanente. Permanente, na razão da inconclusão dos homens e do devenir da realidade. ${ }^{30}$

O devenir da realidade implica na não aceitação do fatalismo do presente. Ou seja, a educação deve servir para a construção do conhecimento que produz uma sociedade melhor do que a atual, a saber, como costumava dizer Hugo Assmann, uma sociedade na qual caibam todos.

\section{FONTES}

BRASIL, Ministério da Educação - MEC. Lei No. 9394/96, de 20 dezembro 1996. Estabelece as Diretrizes e Bases da Educação Nacional. Brasília, 1996.

Blaug, Mark. Introdução à economia da educação. Porto Alegre: Globo, 1975.

Castells, Manuel. A Era da informação: economia, sociedade e cultura. Vol. 3. São Paulo: Paz e terra, 1999.

Chesnais, François. A mundialização do capital. São Paulo: Xamã, 1996.

Deluiz, Neise. O Modelo das Competências Profissionais no Mundo do Trabalho e na Educação: Implicações para o Currículo. Rio de Janeiro, Boletim Técnico do SENAC, v.27, n.3, set/ dez. 2001. Rio de Janeiro: SENAC, 2001. Capturado 21 de agosto de 2008 http: / / www.senac.br / BTS/273/boltec273b.htm.

Ferretti, Celso João. A reforma do Ensino Médio: uma crítica em três níveis. In: BARBOSA, Raquel Lazzari Leite. A Formação de educadores: desafios e perspectivas. São Paulo: UNESP, 2003.

Fidalgo, Fernando. Educação Profissional e a lógica das competências. Petrópolis: Vozes, 2007.

Freire, Paulo. Pedagogia do Oprimido (21ed). Rio de Janeiro: Paz e Terra, 1987.

30 Paulo Freire, Pedagogia do Oprimido (Rio de Janeiro: Paz e Terra, 1987), $72-73$. 
Gentili, Pablo. Educar para o desemprego: a desintegração da promessa integradora In: Frigotto, Gaudêncio. Educação e crise do trabalho: perspectivas de final de século. Petrópolis: Vozes, 2002.

Harvey, David. Condição pós-moderna. São Paulo: Loyola, 2004.

Holanda, Aurélio Buarque. Dicionário da Lingua Portuguesa. São Paulo: Moderna, 2010.

Mello, Guiomar Nano. Cidadania e competitividade: desafios educacionais do terceiro milênio. São Paulo: Cortez, 2002.

Mészáros, István. A educação para além do capital. São Paulo: Boitempo Editorial, 2005.

Oliveira, Maria Auxiliadora Monteiro. Políticas públicas pra o ensino profissional: o processo de desmantelamento dos CEFETs. (Campinas: Papirus, 2003).

Perrenoud, Philippe. Dez novas competências para ensinar. Porto Alegre: Artmed, 2000.

Sevcenko, Nicolau. A corrida para o século XXI: no Loop da Montanha Russa. São Paulo: Companhia das Letras, 2001.

Severino, Antônio Joaquim. Premissas e desafios da pesquisa na pós-graduação em educação: da relevância social ao cuidado epistemológico. In: Perspectivas atuais da pesquisa em educação: Proença-Lopes, Leandro de [et al]. III Encontro de Pesquisa Discente do Programa de Pós-Graduação em Educação da UNINOVE. São Paulo: PPGE/UNINOVE, 2009.

Sung, Jung Mo. Educar para reencantar a vida. Petrópolis: Vozes, 2006.

Weber, Max. "Rejeições religiosas do mundo e suas direções". In: Ensaios de sociologia. 5ed. Rio de Janeiro: Guanabara Koogan, 1982.

\section{REFERÊNCIAS}

Assmann, Hugo, Sung, Jung Mo. Competência e sensibilidade solidária - educar para a esperança. Petrópolis: Vozes, 2000.

Assmann, Hugo. Paradigmas educacionais e corporeidade. Piracicaba: UNIMEP, 1993.

Assmann, Hugo. Metáforas novas para reencantar a educação - epistemologia e didática. (2 ed.) Piracicaba: UNIMEP, 1998.

Assmann, Hugo. Reencantar a Educação: rumo à sociedade aprendente. (7 ed.) Petrópolis: Vozes, 2003.

Assmann, Hugo. Curiosidade e prazer de aprender: o papel da curiosidade na aprendizagem criativa. Petrópolis: Vozes, 2004.

Cohn, Gabriel. Introdução. In Max Weber. Coleção grandes cientistas sociais. (6 ed.) São Paulo: Ática, 1997. 
Durkheim, Èmile. Educação e sociologia. São Paulo: Melhoramentos, 1965.

Ferretti, Celso João [et al]. (Orgs.). Novas tecnologias, trabalho e educação: um debate multidisciplinar. Rio de Janeiro: Vozes, 1994.

Freire, Paulo. Educação como prática da liberdade. (11ed.) Rio de Janeiro: Paz e Terra, 1980.

Lopes, E. M. T. As Origens da Educação Pública. São Paulo: Loyola, 1981.

Luzuriaga, Lorenzo. História da educação pública. São Paulo: Companhia Editora Nacional, 1959.

Reis Filho, Casemiro dos. A educação e a ilusão liberal. São Paulo, Cortez / Autores Associados, 1981.

Silva Jr., João dos Reis e Ferretti, Celso João. O institucional, a organização e a cultura da escola. São Paulo: Xamã, 2004.

Sung, Jung Mo. Conhecimento e solidariedade: educar para a superação da exclusão social. São Paulo: Salesiana, 2002a.

Sung, Jung Mo. Sujeito e sociedades complexas: para repensar os horizontes utópicos. Petrópolis: Vozes, 2002b.

Weber, Max. A ética protestante e o espírito do capitalismo. (5 ed.) São Paulo: Pioneira, 1987.

\begin{tabular}{|l|} 
\\
\hline $\begin{array}{l}\text { De Proença-Lopes, Leandro; De Assis Zaremba, Fellipe. “O discurso de } \\
\text { crise da educação: crítica ao modelo de competências desde a epistemolo- } \\
\text { gia da educação". Revista Historia de la Educación Latinoamericana. Vol. } \\
15 \text { No, 21, (2013): } 283 \text { - } 304 .\end{array}$ \\
\hline
\end{tabular}

